\title{
Assimilating Lagrangian data for parameter estimation in a multiple-inlet system
}

\author{
L.C. Slivinski ${ }^{\mathrm{a}, \mathrm{b}, *}$, L.J. Pratt ${ }^{\mathrm{c}}$, I.I. Rypina ${ }^{\mathrm{c}}$, M. M. Orescanin ${ }^{\mathrm{d}}$, B. Raubenheimer ${ }^{\mathrm{c}}$, \\ J. MacMahan ${ }^{\text {d }}$, S. Elgarc \\ ${ }^{a}$ Cooperative Institute for Research in Environmental Sciences (CIRES), Univ. of Colorado, \\ Boulder, $C O$ \\ ${ }^{b}$ NOAA/Earth System Research Laboratory, Boulder, CO \\ ${ }^{c}$ Woods Hole Oceanographic Institution, Woods Hole, MA \\ ${ }^{d}$ Naval Postgraduate School, Monterey, CA
}

\begin{abstract}
Numerical models of ocean circulation often depend on parameters that must be tuned to match either results from laboratory experiments or field observations. This study demonstrates that an initial, suboptimal estimate of a parameter in a model of a small bay can be improved by assimilating observations of trajectories of passive drifters. The parameter of interest is the Manning's $n$ coefficient of friction in a small inlet of the bay, which had been tuned to match velocity observations from 2011 . In 2013, the geometry of the inlet had changed, and the friction parameter was no longer optimal. Results from synthetic experiments demonstrate that assimilation of drifter trajectories improves the estimate of $n$, both when the drifters are located in the same region as the parameter of interest and when the drifters are located in a different region of the bay. Real drifter trajectories from field experiments in 2013 also are assimilated, and results are compared with velocity observations. When the real drifters are located away from the region of interest, the results depend on the
\end{abstract}

\footnotetext{
*Corresponding author

Email address: laura.slivinski@noaa.gov (L.C. Slivinski)
}

Preprint submitted to Ocean Modelling

March 21, 2017

(C) 2017. This manuscript version is made available under the Elsevier user license http://www.elsevier.com/open-access/userlicense/1.0/ 
time interval (with respect to the full available trajectories) over which assimilation is performed. When the drifters are in the same region as the parameter of interest, the value of $n$ estimated with assimilation yields improved estimates of velocity throughout the bay.

Keywords: Data assimilation, modelling, drag coefficient, drifters, tidal inlets

1

2

3

5

6

7

8

9

\section{Introduction}

Bottom stress is important to circulation in shallow water, and its inclusion in numerical models can have significant impacts on the simulation results. However, it is difficult to measure spatially-varying bottom stress directly in the field (Trowbridge et al., 1999; Sanford and Lien, 1999; Biron et al., 2004), and thus often stress is approximated with a bottom drag coefficient derived from laboratory experiments or by tuning numerical model simulations to observations, which usually involves iterations of model results that are time-consuming and costly (Cheng et al., 1999; Chen et al., 2015; Orescanin et al., 2016). Drag coefficients also can be estimated from observations of the flow by assuming a balance between pressure gradients and bottom stress (Feddersen et al., 2000; Seim et al., 2002; Apotsos et al., 2008; Kim et al., 2000; Orescanin et al., 2014). These coefficients have been estimated in other regions by assimilating sea-level data into numerical simulations (Mayo et al., 2014). Here, the Manning's $n$ drag coefficient in a multiple tidal inlet system on Martha's Vineyard, MA is estimated by assimilating observed Lagrangian drifter trajectories into a numerical model for sea level and circulation.

Martha's Vineyard is separated from Chappaquiddick Island by Katama Bay, which is connected to Vineyard Sound via Edgartown Channel and to the Atlantic Ocean via the ephemeral Katama Inlet (Figure 1A). Norton Point, the sand spit between the bay and the Atlantic, was breached by a storm in 2007 (yellow arrow, 

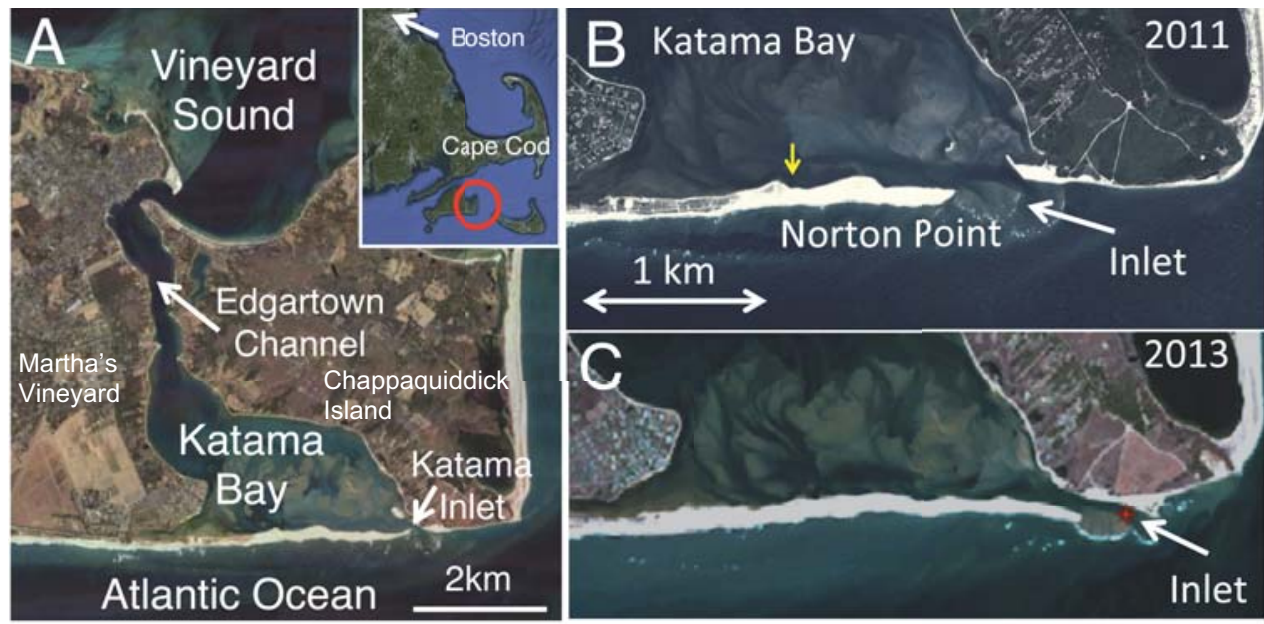

Figure 1: A) Satellite image (Google Earth, 2012) of Katama Bay, Katama Inlet, and Edgartown Channel, with an inset showing the location of Katama Bay (red circle on Martha's Vineyard) relative to Boston and Cape Cod, B) Katama Inlet in 2011 showing the location of the initial breach of Norton Point (yellow arrow), and C) Katama Inlet in 2013 during drifter deployments.

Figure 1B), forming Katama Inlet. Over the following years, the inlet became narrower, longer, and shallower as it migrated eastward (Figure 1B, C), and friction became more important to sea level and circulation in the bay (Orescanin et al., 2016).

Data assimilation provides a framework for combining uncertain estimates from numerical models with noisy observations to estimate a variable that changes in time (Kalnay, 2003). For geophysical fluid flows, velocity fields and bathymetry can be estimated by assimilating Eulerian observations from in-situ sensors (Madsen and Cañizares, 1999; Oke et al., 2002; Kurapov et al., 2005; Wilson et al., 2010) or Lagrangian observations from drifting sensors (Ide et al., 2002; Mariano et al., 2002; Molcard et al., 2005, 2006; Salman et al., 2006; Apte et al., 2008). Drifters follow (approximately) the motion of fluid parcels, and assimilation of their trajectories leads to improved estimates of large-scale circulation patterns (Taillandier et al., 
2006; Jacobs et al., 2014) and flows in vortices (Vernieres et al., 2011). Lagrangian observations also have been assimilated in models that estimate the topography in a laboratory channel (Honnorat et al., 2010) and the bathymetry in a river (Landon et al., 2014). Synthetic experiments have compared the Eulerian flow fields estimated by assimilating velocities derived from Lagrangian data (so-called pseudo-Lagrangian data assimilation) and by assimilating Lagrangian trajectories directly, and the results show that the direct assimilation of trajectories outperforms pseudo-Lagrangian data assimilation (Molcard et al., 2003).

In 2011, when Katama Inlet was open (Figure 1B), current meters were deployed throughout the bay (Orescanin et al., 2014, 2016). A numerical model (ADCIRC, Luettich and Westerink (1991)) of the circulation in the bay at this time was developed, using boundary conditions from pressure gauges deployed in 2011, and the Manning's $n$ coefficient in the region of Katama Inlet was tuned to match the data from the current meters in 2011. In 2013, after the inlet had begun to migrate and narrow (Figure 1C), current meters were again deployed throughout the bay. Results from the numerical model using boundary conditions from the gauges deployed in 2013, but with the same estimates of Manning's $n$ from 2011, were compared with the 2013 observations from the current meters. Orescanin et al. (2016) found that discrepancies between the 2013 observations and the numerical model were due to changes in friction, and therefore, the value of Manning's $n$ in Katama Inlet estimated from 2011 data was suboptimal when modeling the 2013 system.

Here, drifter tracks observed in the Katama Bay system are assimilated into a numerical circulation model (ADCIRC) to estimate the bottom friction. The model uses bathymetry measured throughout the system and is driven with observed tides, and simulations with and without assimilating drifter data are compared with Eulerian observations of currents in Katama Bay. As a proof of concept, synthetic 
observation experiments are performed first. Experiments assimilating real drifter data are performed next. Results from assimilating synthetic and real drifter trajectories in two distinct regions of Katama Bay are compared.

\section{Numerical model and observations}

\subsection{Numerical model of Katama Bay}

Sea level and depth-averaged currents in Katama Bay are simulated with the two-dimensional version of the Advanced Circulation Model (ADCIRC, Luettich and Westerink (1991)), which solves a version of the shallow water equations via a finite-element method. This model assumes no stratification in the domain; this was supported by observations in Katama Bay. Casts from CTD (conductivity, temperature, depth) instruments throughout the system show little to no temperature or salinity stratification. Within the bay, the depths are very shallow, so this is expected. Offshore in Vineyard Sound and the Atlantic, in depths less than 10m, the same lack of vertical structure was observed. Winds were light $(<2 \mathrm{~m} / \mathrm{s})$ and waves were small $(<1 \mathrm{~m})$ during the drifter deployment periods, and are not included here. The numerical grid consists of a finite-element triangular mesh with spacing ranging from $10 \mathrm{~m}$ in the inlets and $15 \mathrm{~m}$ in the bay to $200 \mathrm{~m}$ outside the inlets in both the Atlantic Ocean and Vineyard Sound (Figure 2A). Bathymetry (5 to $20 \mathrm{~m}$ horizontal and $0.05 \mathrm{~m}$ vertical resolution) in the bay, the inlets, and the ebb tidal delta (Figure 2A) was measured in 2013 with GPS and an acoustic altimeter mounted on a personal water craft, and interpolated onto the model grid (Orescanin et al., 2016). Pressure gauges and current meters were co-located at ten locations within Edgartown Channel, Katama Bay, and Katama Inlet (orange circles in Figure 3) (Orescanin et al., 2016). The northern boundary of the model is forced with 
the sea-level observations in Edgartown Harbor (yellow circle in Figure 2A), and the southern boundary is forced with observations from the Martha's Vineyard Coastal Observatory (12 m depth, $4 \mathrm{~km}$ west of Katama Inlet; not shown).

To estimate quadratic bottom stress, the model converts bottom roughness given by a user-defined value of Manning's $n$ (units $\mathrm{s} / \mathrm{m}^{1 / 3}$ ) at each node to an equivalent quadratic drag coefficient given by:

$$
C_{d}(t)=\frac{g n^{2}}{(D+\eta(t))^{1 / 3}},
$$

where $g$ is gravity, $t$ is time, $D$ is the local mean depth, and $\eta(t)$ is the water surface elevation above $D$ (Luettich and Westerink, 1991).

The Katama Bay domain is divided into several subregions based on bathymetry, each with a different value of Manning's $n$ (see Figure 2B.) In the original 2011 simulations, the deep boundary regions (dark blue in Figure 2B) outside of the bay were assigned the value $n=0.020 \mathrm{~s} / \mathrm{m}^{1 / 3}$, which is standard for open water. The bay (light blue) was assigned $n=0.030 \mathrm{~s} / \mathrm{m}^{1 / 3}$, which was calculated by converting the bottom stress estimated from a pressure gradient balance (Orescanin et al., 2014) into $n$ using an average depth of the bay. However, model-data comparisons (Orescanin et al., 2016) suggested that the friction coefficient needed to be increased to $n=0.035 \mathrm{~s} / \mathrm{m}^{1 / 3}$ in an area surrounding Katama Inlet (green area in Figure 2B) in 2011. This spatial and temporal variation in $n$ is due mainly to changes in bedforms; for example, sand waves and dunes were observed throughout the system, and tended to migrate over time. These values of Manning's $n$ are typical in tidal inlets, including multiple tidal inlet systems (Mehta and Joshi, 1998; Kraus and Militello, 1999; Friedrichs and Madsen, 1992; Friedrichs, 1995; Dias et al., 2009).

By iteratively simulating the 2011 circulation, Manning's $n$ was estimated as the 
value that minimized the difference between observed and simulated kinetic energy in the bay circulation (Orescanin et al., 2016). The tuning required several different model simulations, as well as a method for determining which value is optimal, because varying $n$ can improve kinetic energy estimates in the inlet while degrading estimates elsewhere in the bay. For the estimation of the 2011 circulation, the root mean squared errors between the simulated and observed velocity kinetic energies, tidal currents, and sea-level amplitudes and phases were minimized. In particular, $n$ was tuned until the errors at each of the seven observation locations were less than $15 \%$, while minimizing the total error throughout the domain (Orescanin et al., 2016, especially Table 1). The Katama Inlet bathymetry changed substantially between 2011 and 2013 (compare Figure 1C with 1B), and simulations using the 2013 bathymetry and the 2011-estimated $n$ had decreased skill within Katama Inlet (Orescanin et al., 2016). Note also that the flow has the greatest velocities in the inlet, and therefore changes in $n$ here have large effects throughout the system (Orescanin et al., 2016). Here, Lagrangian drifter data from 2013 field experiments are assimilated into the model to improve the estimates of friction in Katama Inlet in 2013.

\subsection{Drifter observations in 2013}

In August 2013, several drifter deployments were conducted with twelve drifters released in multiple deployments over several days. On Aug 20, the drifters targeted Edgartown Channel, and on Aug 22, they targeted Katama Inlet (Figure 3). The surface tracking drifters used herein are a modified version of drifters deployed in the surf zone (MacMahan et al., 2009; Fiorentino et al., 2012) and rivers (Landon et al., 2014), both in body shape and type of handheld GPS. These drifters were deployed together in the inner shelf and visually behaved similarly. The GPS used on the 2013 

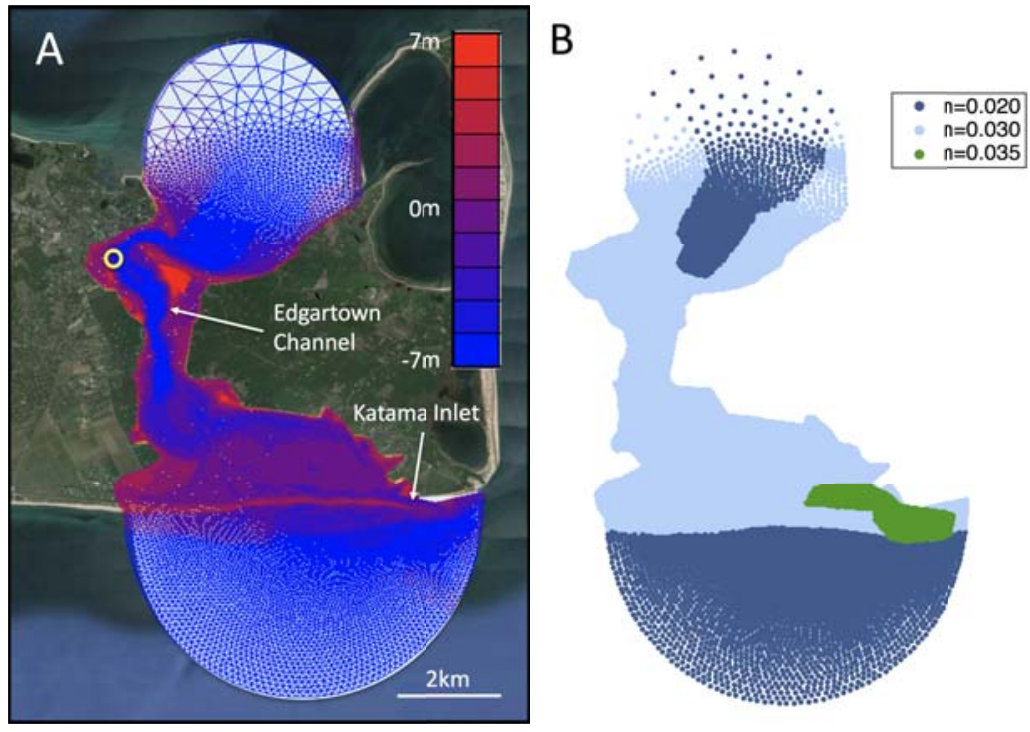

Figure 2: A) Google Earth image of the Katama system with seafloor and land elevation contours (colors, scale on right), the grid mesh, and the Edgartown Harbor pressure gauge (yellow circle) and B) the bathymetrically-defined subregions with different friction factors $(n$; values for the colors are given in the legend, units $\mathrm{s} / \mathrm{m}^{1 / 3}$ ). 


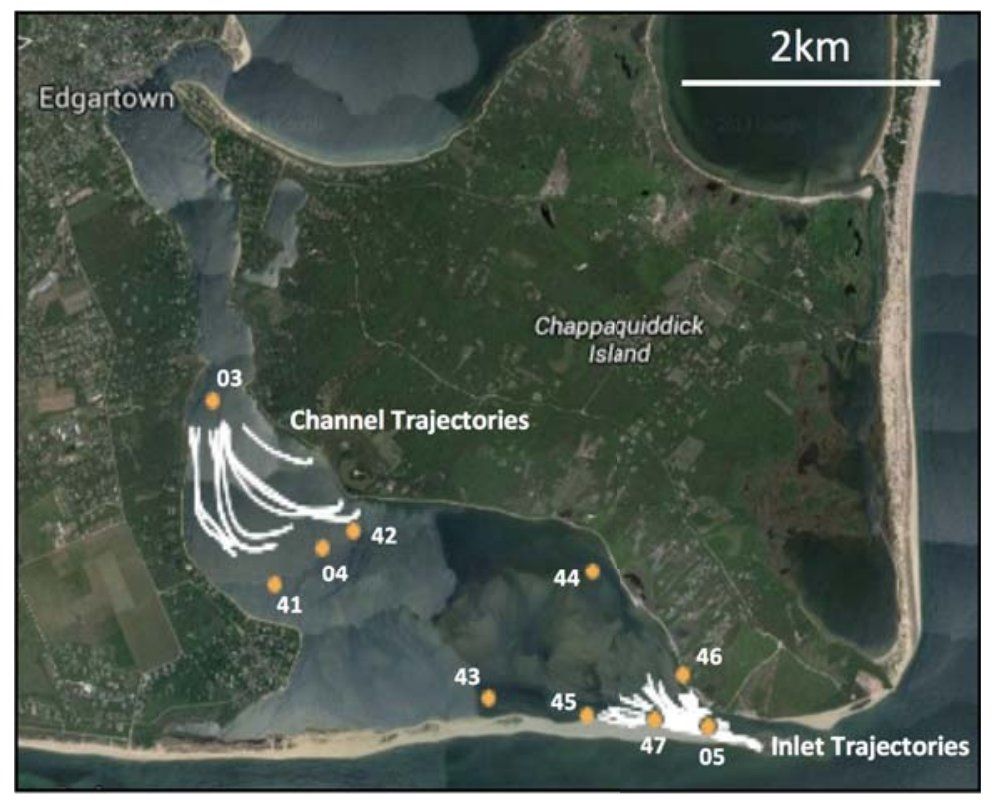

Figure 3: Trajectories of real drifters deployed Aug 20, 2013 for approximately 140 minutes (Channel Trajectories) and Aug 22, 2013 for approximately 110 minutes (Inlet Trajectories) in Katama Bay. Orange circles are locations of acoustic Doppler current meters (water depths $<2 \mathrm{~m}$ ) and profilers (depths $>2 \mathrm{~m}$ ).

Katama drifters is a Locosys GT-31, which provides accurate relative position useful for velocity measurements. The Locosys GPS has successfully measured surfzone velocities and trajectories (McCarroll et al., 2014) and surface gravity wave elevations (Herbers et al., 2012). The inlet drifters were also deployed as part of an experiment in the inner shelf of the Gulf of Mexico. The drifter trajectories compared well to acoustic Doppler current profiler (ADCP) surface velocity estimated trajectories (Roth et al., submitted). 


\section{Overview of Lagrangian data assimilation}

Lagrangian data can be assimilated directly or indirectly. In pseudo-Lagrangian data assimilation (Molcard et al., 2003), sequential positions of the drifters are converted to Lagrangian velocities, which are then assimilated into the model. Fully Lagrangian data assimilation uses the positions of the drifters directly, such as in the augmented vector approach (Kuznetsov et al., 2003), in which the positions of the drifters are appended to the state vector at each time step. With this approach, to assimilate observations of a single drifter following the flow into a two-dimensional velocity field, the augmented vector at time $t$ is $[u, v, x, y](t)$, where $u$ and $v$ are a representation of the velocity field at each model grid point at time $t$, and $(x, y)$ is the position of the drifter at that time.

Here, the focus is on estimating $n$ as a parameterization of the flow field, so the state vector is $\left[n, x_{1}, y_{1}, \ldots x_{N_{D}}, y_{N_{D}}\right]$ for $N_{D}$ drifters. The velocity $[u, v]$ is not estimated directly from the assimilation, and thus does not appear in the state vector, although the evolution of the drifter positions depends on the time-variable velocity field, which depends on $n$.

\subsection{Ensemble Kalman Filter}

The data assimilation method used here is the ensemble Kalman filter (EnKF) (Evensen, 1994), which is used both operationally (Wei et al., 2006) and in test problems, including Lagrangian data assimilation (Salman et al., 2006, 2008). The EnKF assimilates consecutive observations serially. At each time step, the best estimate and a quantification of its uncertainty are provided by an ensemble of possible realizations. When an observation is available, the ensemble is updated to reflect the new information. Here, the EnKF is reviewed briefly in the context of Lagrangian data assimilation for parameter estimation. 
Let the state vector be given by $\mathbf{z}(t)=\left[n, x_{1}(t), y_{1}(t), \ldots x_{N_{D}}(t), y_{N_{D}}(t)\right]$. At times $t_{1}, t_{2}, \ldots t_{f}$ drifters are observed at positions $\mathbf{q}_{o b s}$, so that

$$
\mathbf{q}_{\text {obs }}\left(t_{k}\right)=\mathbf{H z}_{\mathbf{z}}\left(t_{k}\right)+\epsilon_{k}
$$

where $\mathbf{H}=\left[\begin{array}{ll}0 & \mathbf{I}\end{array}\right]$ is the observation operator in the augmented vector setup, and $\epsilon_{k} \sim \mathcal{N}(0, \mathbf{R})$ where $\mathbf{R}$ is the observational error covariance. The observation errors are assumed to be uncorrelated in time, independent, and Gaussian so that $\mathbf{R}=\sigma_{R}^{2} \mathbf{I}$ is diagonal.

Assume that at time $t_{k-1}$, there is an ensemble $\left\{\mathbf{z}_{i}\left(t_{k-1}\right)\right\}$ for $i=1 \ldots N_{e}$, and the next available observation is at time $t_{k}$. The forecast ensemble is computed by evolving each ensemble member forward under the dynamics. Although the parameter being estimated could evolve under a dynamic model as well, here the parameter remains the same between observation times, but the flow determined by that parameter evolves according to the numerical model (in this case, ADCIRC.) Each ensemble member's drifters simultaneously are advected passively under that velocity field, giving the forecast ensemble at time $t_{k},\left\{\mathbf{z}_{i}^{f}\left(t_{k}\right)\right\}$, which will be updated to reflect the observation. The EnKF update step, also known as the analysis step, is applied to each ensemble member according to:

$$
\begin{aligned}
\mathbf{z}_{i}^{a} & =\mathbf{z}_{i}^{f}+\mathbf{P}^{f} \mathbf{H}^{\mathrm{T}}\left(\mathbf{H} \mathbf{P}^{f} \mathbf{H}^{\mathrm{T}}+\mathbf{R}\right)^{-1}\left(\mathbf{H z}_{i}^{f}-\left[\mathbf{q}_{\text {obs }}+\eta_{i}\right]\right) \\
\mathbf{P}^{f} & =\frac{1}{N_{e}-1} \sum_{i=1}^{N_{e}}\left(\mathbf{z}_{i}^{f}-\overline{\mathbf{z}}^{f}\right)\left(\mathbf{z}_{i}^{f}-\overline{\mathbf{z}}^{f}\right)^{\mathrm{T}}
\end{aligned}
$$

where $\mathbf{P}^{f}$ is the sample covariance of the forecast ensemble and $\eta_{i} \sim \mathcal{N}(0, \mathbf{R})$ for the perturbed observation formulation of the EnKF (Evensen, 2003). This step takes place entirely at time $t_{k}$, and thus the time dependence has been dropped. The 
forecast-analysis cycle is then repeated for each available consecutive observation time.

Here, the scalar Manning's $n$ in the Katama Inlet area (green region in Figure 2) is estimated using drifter trajectories located throughout the bay. Thus, only $n$ and the drifter positions are updated at each analysis step; in the forecast step, the full velocity and elevation fields of the entire domain evolve according to ADCIRC with the latest updated value of $n$ in Katama Inlet.

\subsection{Observing system simulation experiments}

The method is tested in an artificial scenario known as an observing system simulation experiment (OSSE), in which the same model used in the forecast step of the assimilation method also is used to create a synthetic truth consisting of time series of both the velocity field and the drifter positions. Random (Gaussian) perturbations are then added to the true drifter trajectories to simulate noisy observations. An initial ensemble of the flow and drifters is generated by perturbing the true initial value of Manning's $n$ in Katama Inlet and the true drifter positions. This yields an ensemble of different flow states, each consistent with a perturbed value of $n$, and each with different initial drifter positions. The performance of the data assimilation method is then judged based on its ability to recover the true value of $n$ in the inlet from the perturbed initial ensemble and the noisy observations.

Two OSSEs are run. One assimilates drifter trajectories from Katama Inlet (thick white curves in Figure 4), and the other assimilates trajectories from Edgartown Channel, located north of the inlet subdomain (thin white curves in Figure 4). The drifter release times and locations are designed to mimic the real data available from August 2013. In both experiments, the synthetic truth is a 6-hour time series of the velocity field generated with Manning's $n=0.035 \mathrm{~s} / \mathrm{m}^{1 / 3}$ in the inlet and 
the trajectories from 13 drifters. The initial ensemble of drag coefficients $\left\{n_{i}\right\}$ for $i=1 \ldots N_{e}=30$ is drawn from a normal distribution with mean $0.025 \mathrm{~s} / \mathrm{m}^{1 / 3}$ and standard deviation $0.005 \mathrm{~s} / \mathrm{m}^{1 / 3}$. This is a common ensemble size for this size problem (Houtekamer and Mitchell, 2001; Mitchell et al., 2002; Evensen, 2003). Decreasing the ensemble size to $N_{e}=10$ degrades the performance, but $N_{e}=20$ yields similar results as $N_{e}=30$. In practice, some a priori knowledge of the feasible range of values is necessary in order to choose the initial ensemble mean and spread. For the synthetic experiments here, the initial ensemble is defined relatively far from the truth (the mean is two standard deviations less than the true value of $n$ ) to determine whether the assimilation can recover the truth even under these conditions.

The observation error of the drifters has mean 0 and standard deviation $\sigma_{R}=$ $25 \mathrm{~m}$. This is larger than the value of approximately $2 \mathrm{~m}$ given by MacMahan et al. (2009) as the error of the real drifter positions, to prevent the assimilation ensemble from collapsing onto the observations too quickly and resulting in filter divergence. Here, "filter divergence" refers to the collapse of the ensemble onto the incorrect estimate of $n$, but it could also result in an estimate of the uncertainty surrounding $n$ that is not large enough (due to an ensemble spread that is too small). Filter divergence is often a result of applying an approximately linear method (that is, the EnKF) to a nonlinear problem (such as drifter trajectories in a nonlinear flow) and has been demonstrated in the Lagrangian data assimilation setup (Apte et al., 2008; Slivinski et al., 2015). In a system that has only weakly nonlinear characteristics, the EnKF can avoid divergence if larger errors are included (Mitchell et al., 2002). Although overestimating observation error can potentially have detrimental effects, such as increasing the time it takes for the ensemble estimate to converge and providing an artificial lower bound on the errors in the estimates, the results in the following section suggest that the assimilation worked well with the chosen values: 


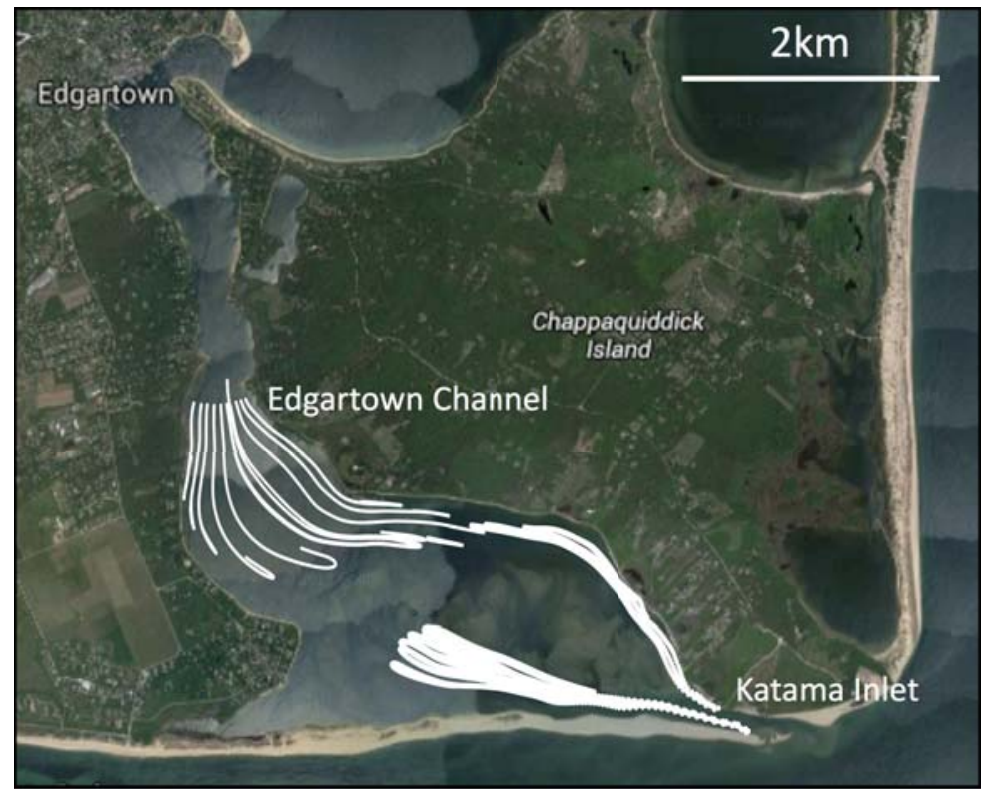

Figure 4: Synthetic drifter trajectories in Katama Bay. Thin white trajectories are from the drifters released on model date Aug 20 in Edgartown Channel, and thick white trajectories are from drifters released on model date Aug 22 just outside Katama Inlet.

the ensemble does not collapse too early nor does it diverge. The time between subsequent observations $\Delta t$ is tested for $\Delta t=1,5$, and $10 \mathrm{~min}$. The velocity fields for both the synthetic truth and the initial ensemble are spun up with their respective values of $n$ for several days, so that all the simulations have reached equilibrium before assimilation begins.

\section{Results from synthetic experiments}

\subsection{Drifters within the subdomain of interest}

OSSEs are run with drifters released just outside Katama Inlet when the flow is from south to north into the inlet, through the bay, and out through Edgartown Channel to Vineyard Sound. The drifter deployment times and locations are chosen 
to mimic the real observations, so $N_{D}=13$ synthetic drifters are released (in the numerical model) just outside the inlet starting at 8:30 am (EDT) Aug 22, 2013. To study the convergence of the estimates of $n$, the data are assimilated over a period of 6 hours, significantly longer than the 1-2 hour-long time windows of the real drifter observations.

For each of the $\Delta t$, the assimilation estimates $n$ fairly well, converging after about 60 minutes (Figure 5). However, for $\Delta t=10 \mathrm{~min}$, the assimilation initially overestimates $n$ slightly, and gradually decreases to the truth over the six hour window (Figure 5C).

The estimates of kinetic energy, defined as 0.5 times the sum of squared velocity over all grid points $i: \frac{1}{2} \sum_{i}\left(u_{i}^{2}+v_{i}^{2}\right)$ for the three data assimilation experiments, also converge within 60 min to the synthetic true values (Figure 6 (A-C)). A "free run", in which the initial ensemble members are each integrated forward without assimilation for 6 hours with the initial value of $n$ remaining constant, has poorer performance than the assimilation runs (compare Figure 6D with A-C). These results demonstrate that changing the friction (via assimilation) on these time scales has near-immediate effects on the total kinetic energy in the model, and thus, the assimilated ensemble predicts the correct kinetic energy as quickly as it estimates the correct value of the drag coefficient.

\subsection{Drifters in Edgartown Channel}

Three additional experiments are run with the same setup as above, but with the drifters released in Edgartown Channel. Again, the deployment time (10:40 am Aug $20,2013)$ and initial locations of the 13 drifters are chosen to match the real data, and observations are assimilated for six hours for $\Delta t=1,5$, and $10 \mathrm{~min}$. Although the drifters never approach the inlet subdomain in which the drag coefficient is estimated, 


\section{Manning's $n$, Aug 22 (Katama Inlet)}
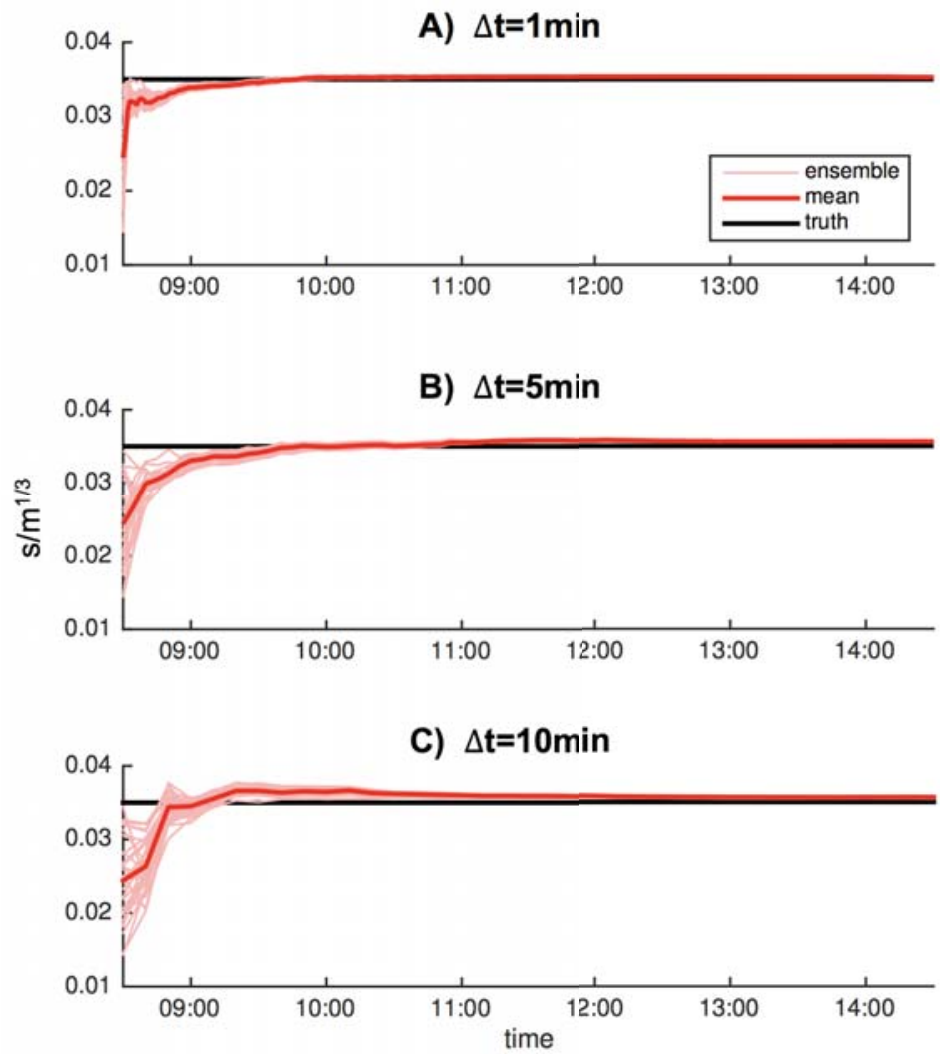

Figure 5: Ensemble (thin light red curves) and mean (thick red curves) estimates for Manning's $n$ versus assimilation time on Aug 22, when drifters were released in Katama Inlet, for $\Delta t=(\mathrm{A}) 1$, (B) 5 , and (C) 10 min. The black line is $n=0.035 \mathrm{~s} / \mathrm{m}^{1 / 3}$. 


\section{Kinetic energy, Aug 22 (Katama Inlet)}

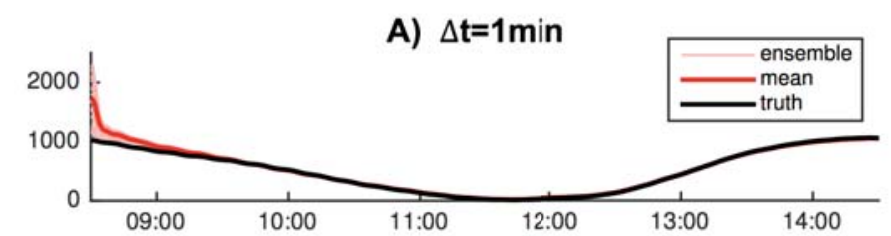

B) $\Delta t=5 \mathrm{~min}$

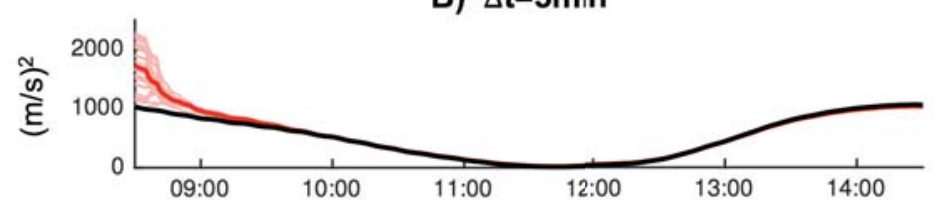

C) $\Delta t=10 \mathrm{~min}$
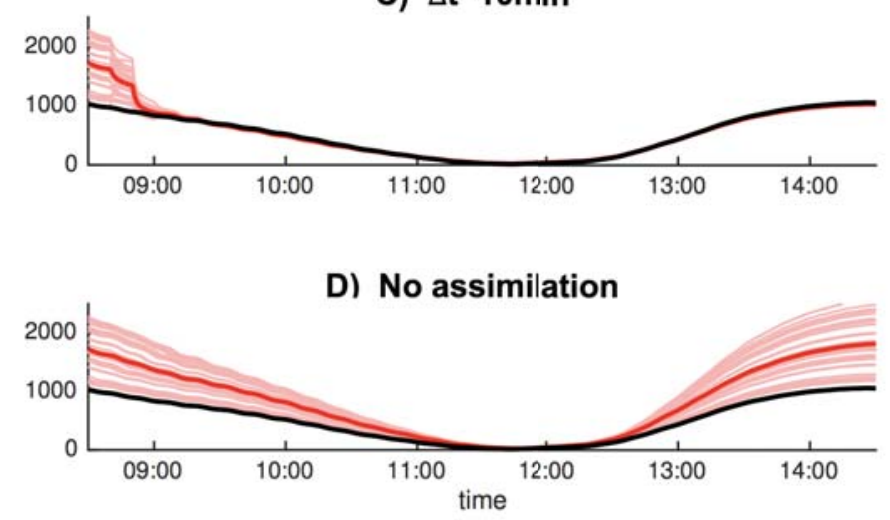

Figure 6: Ensemble (thin light red curves) and mean (thick red curves) estimates of kinetic energy versus assimilation time on Aug 22, when drifters were released in Katama Inlet, for $\Delta t=(\mathrm{A}) 1$, (B) 5, and (C) $10 \mathrm{~min}$, as well as the case with no data assimilation (D). The black curves are the synthetic "truth" from the simulation with $n=0.035 \mathrm{~s} / \mathrm{m}^{1 / 3}$. 
the assimilation converges to the correct "true" value of $n$ (Figure 7). However, assimilating drifters in Edgartown Channel results in a longer time to convergence than assimilating drifters in the inlet. For $\Delta t=1 \mathrm{~min}$, the ensemble takes about 90 minutes to converge onto the truth (Figure 7A), and for $\Delta t=10 \mathrm{~min}$, it takes about 2 hours (Figure $7 \mathrm{C}$ ). For $\Delta t=5 \mathrm{~min}$, the ensemble initially diverges from the truth, and takes approximately 6 hrs to converge (Figure $7 \mathrm{~B}$ ). This is likely due to a combination of nonlinearity and random noise that has a stronger effect on the assimilation when the observations are farther away from the region of interest, and is discussed below in more detail. Similar to the releases in Katama Inlet (Figure 6), assimilation estimates of the kinetic energy converge to the true values at the same rate as $n$ converges (Figure 8).

\subsection{Discussion}

As expected, the assimilation of drifters in the same spatial location (Katama Inlet) as the estimated $n$ leads to quicker convergence to the true $n$ than the assimilation of drifters in Edgartown Channel. This is consistent with the results of Salman et al. (2008), who showed that local structures within a flow field are wellapproximated when the drifters stay close to those structures (eg, when the drifters are trapped in a vortex), whereas global flow properties are estimated best when the drifters cover most of the domain (eg, when the drifters are spread out and some follow a jet stream in the flow). Therefore, the performance of the Lagrangian data assimilation algorithm will depend on the spatial location of the drifters and their trajectories.

Although the performance degrades slightly when the time between observations of drifters in Katama Inlet is increased, the assimilation estimates the correct value of $n$ within about an hour for each $\Delta t$. Conversely, when drifters in Edgartown 


\section{Manning's $n$, Aug 20 (Edgartown Channel)}
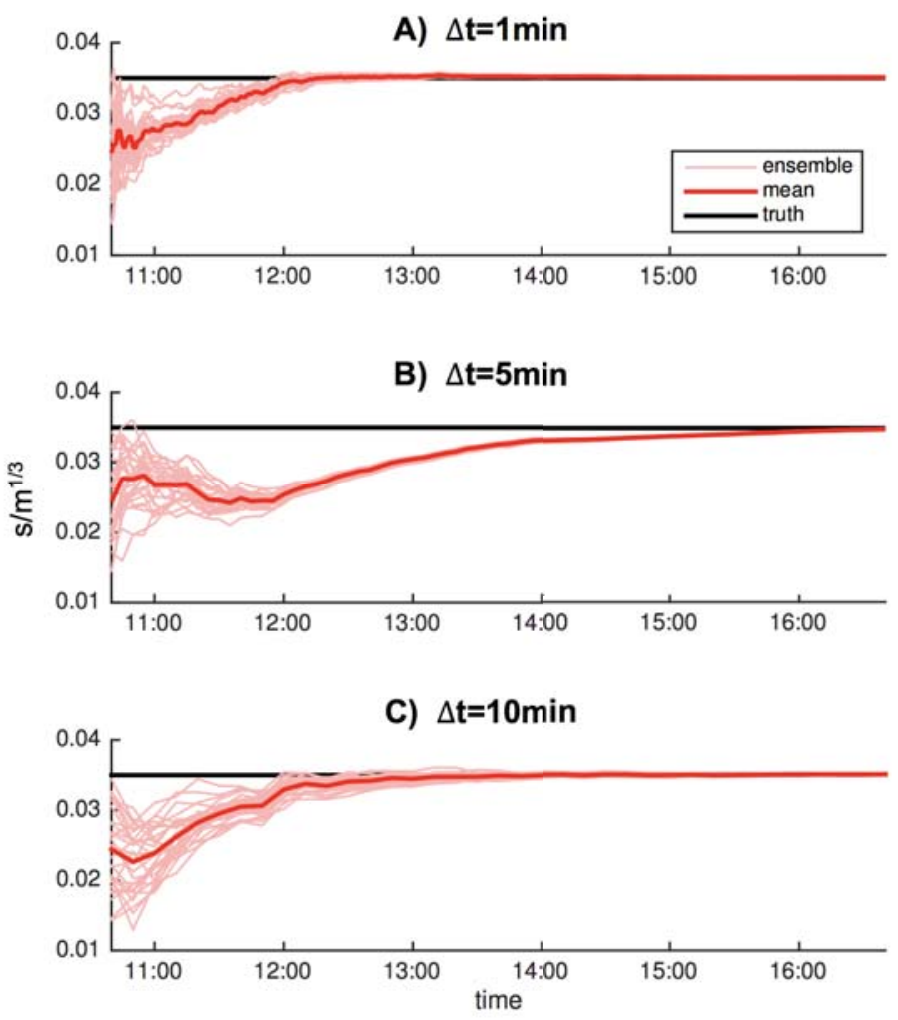

Figure 7: Ensemble (thin light red curves) and mean (thick red curves) estimates of Manning's $n$ versus assimilation time on Aug 20, when drifters were released in Edgartown Channel, for $\Delta t=$ (A) 1, (B) 5, and (C) 10 min. The black line is $n=0.035 \mathrm{~s} / \mathrm{m}^{1 / 3}$. 


\section{Kinetic energy, Aug 20 (Edgartown Channel)}

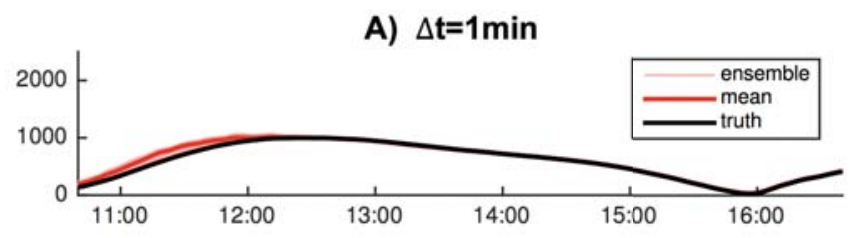

B) $\Delta t=5 \mathrm{~min}$

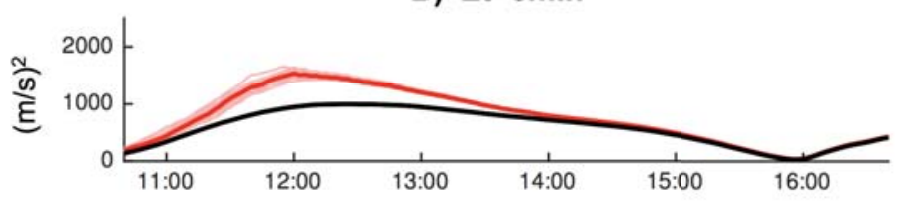

C) $\Delta t=10 \mathrm{~min}$

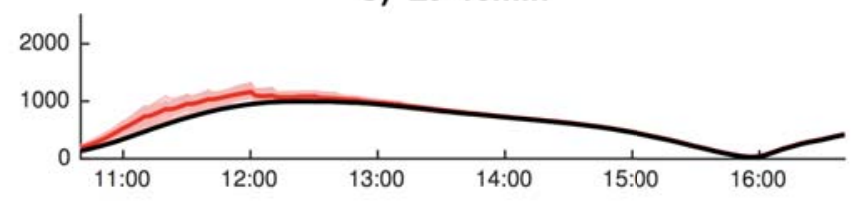

D) No assimilation

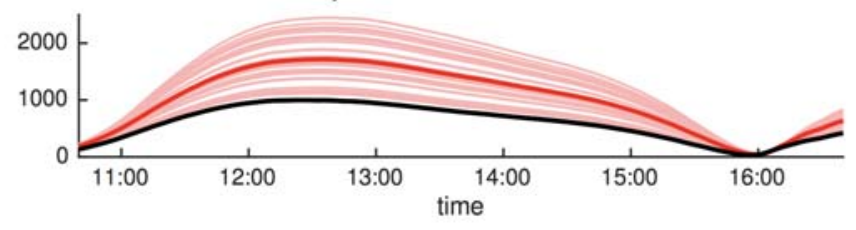

Figure 8: Ensemble (thin light red curves) and mean (thick red curves) estimates of kinetic energy versus assimilation time on Aug 20, when drifters were released in Edgartown Channel, for $\Delta t=$ (A) 1, (B) 5, and (C) 10 min, as well as the case with no data assimilation (D). The black curves are the synthetic "truth" from the simulation with $n=0.035 \mathrm{~s} / \mathrm{m}^{1 / 3}$. 
Channel are assimilated, the performance of the assimilation depends more strongly on the time between observations, and does not improve monotonically as the time between observations decreases.

To determine why assimilating trajectories from Katama Inlet results in significantly faster convergence than assimilating Edgartown Channel trajectories, especially for intermediate $\Delta t=5 \mathrm{~min}$, consider the time it takes the kinetic energy in the bay to adjust and equalize after an abrupt change in the drag coefficient in the inlet. A crude approximation of the adjustment time is the time required for a long gravity wave to propagate over the largest dimension of the bay $l_{\max }$ in water depth $d$, and for a reflected wave to return to the source over the same path:

$$
\begin{aligned}
T_{\text {adjustment }} & \approx 2\left(\frac{l_{\max }}{\sqrt{g d}}\right) \\
& \approx 2\left(\frac{2 \times 10^{3} m}{(9.8 * 4)^{1 / 2} \mathrm{~m} / \mathrm{s}}\right) \\
& \approx 600 \mathrm{~s} .
\end{aligned}
$$

Thus, the intrinsic time for Katama Bay to adjust to changes in $n$ in the inlet is approximately $10 \mathrm{~min}$.

To determine how long it takes the velocity field and the drifters to adjust to the new value of Manning's $n$, the system was run for 4 days with $n=0.035 \mathrm{~s} / \mathrm{m}^{1 / 3}$ in the inlet and constant north-to-south tidal forcing, similar to the case when the drifters are released in Edgartown Channel. At the beginning of the fifth day, simulations with $n=0.01,0.02,0.03,0.035,0.04,0.05$, and $0.06 \mathrm{~s} / \mathrm{m}^{1 / 3}$ were run. In each experiment, drifters are released in Edgartown Channel at the same locations as the synthetic experiment above. Each situation is simulated for $1 \mathrm{hr}$, with no assimilation. 


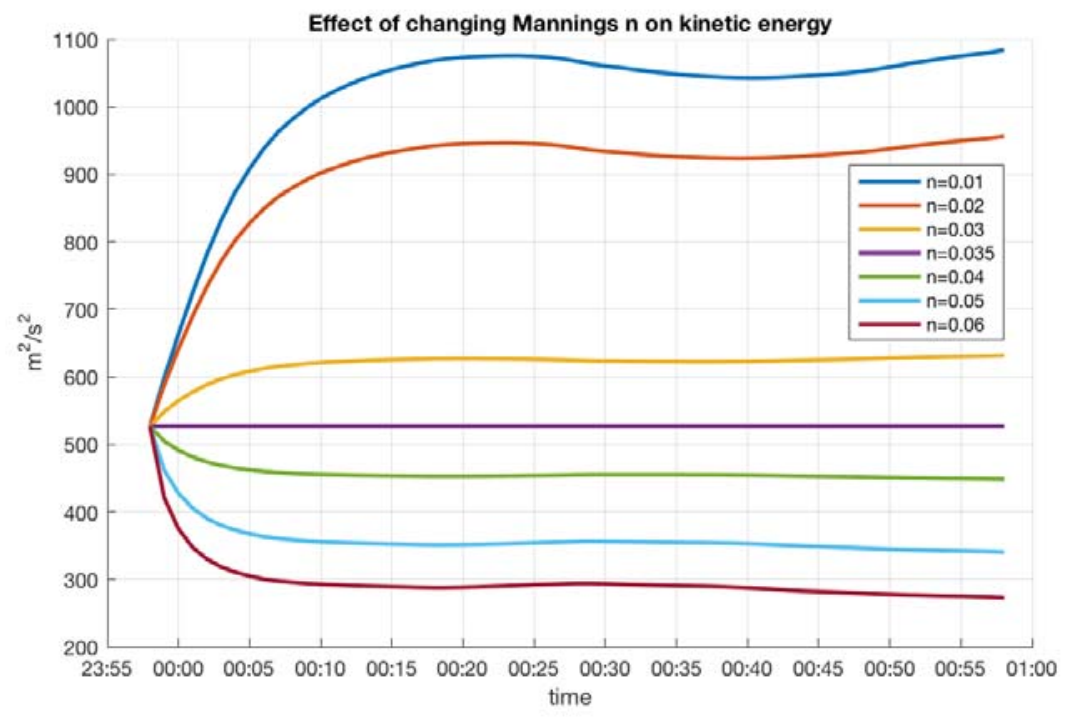

Figure 9: Kinetic energy spatially averaged over the entire domain versus time for different initial values of $n$ (colors in the legend; units $\mathrm{s} / \mathrm{m}^{1 / 3}$ ) in the inlet.

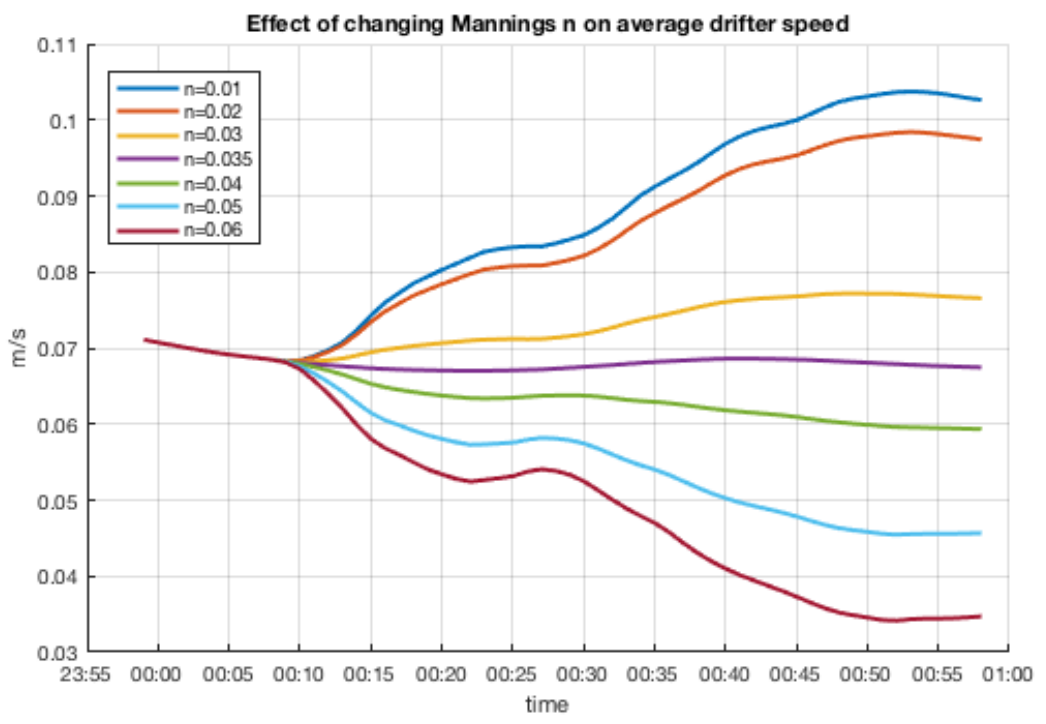

Figure 10: Average speed of 13 drifters released in Edgartown Channel versus time for different initial values of $n$ (colors in the legend) in the inlet. 
For a range of initial values of $n$, the kinetic energy averaged over the entire domain converges about 25 minutes after $n$ is changed, although for the simulations with the largest and smallest values of $n$, the kinetic energy oscillates slowly (Figure 9). A change of $0.005 \mathrm{~s} / \mathrm{m}^{1 / 3}$ in $n$ from the true values results in convergence after about $10 \mathrm{~min}$. Changing $n$ by $0.025 \mathrm{~s} / \mathrm{m}^{1 / 3}$ results in about a $50 \%$ change in kinetic energy (e.g., compare the blue $(n=0.010)$ with the purple $(n=0.035)$ curve and compare the purple $(n=0.035)$ with the red $(n=0.060)$ curve in Figure 9$)$.

For the first 10 min after the change, the average speed of the drifters released in Edgartown Channel does not depend on the initial value of $n$ (Figure 10). The model simulates drifter advection with a 4th order Runge-Kutta scheme with a 1-min time step, and the simulations suggest that changes in the friction in Katama Inlet do not have an effect on the drifters in Edgartown Channel for at least 10 min, consistent with Eq. 4.

It is unsurprising, then, that the assimilation takes longer to converge when the drifter observations are located in the channel than when they are in the inlet: information takes longer to travel between Katama Inlet and Edgartown Channel than it does within the inlet. Due to the nature of the data assimilation method, which combines uncertain forecasts with the noisy observations, the increment made to $n$ at each analysis step is generally no more than $0.005 \mathrm{~s} / \mathrm{m}^{1 / 3}$. In this regime, there is very little effect on the average drifter speed before fifteen minutes, so the assimilated drifter trajectories will likely not reflect the changes in $n$ within one assimilation step of any size studied here. Therefore, small differences in realizations of noise (in the drifter observations) could affect the timescale of convergence of $n$ fairly strongly when the drifters are in the channel.

To this end, experiments identical to the ones earlier in this section are run (results not shown), but with different realizations of observation noise, sampled from the 
same Gaussian distribution as the previous experiment. The second experiment with drifters in Katama Inlet performs almost identically to the inlet experiment shown above: the ensemble has converged onto the true value within an hour, with the best performance for $\Delta t=1$ minute. However, the experiment that assimilates drifters in Edgartown Channel produces fairly different results from the experiment above. For $\Delta t=1 \mathrm{~min}$ and $\Delta t=5 \mathrm{~min}$, the ensembles each take about 4 hours to converge, more than twice the time for the experiment with $\Delta t=1 \mathrm{~min}$ above, but significantly less time than the experiment with $\Delta t=5 \mathrm{~min}$ above. The experiment with $\Delta t=10$ min results in about a 2.5 hour convergence time for the second realization of noise, as compared to the convergence time of $90 \mathrm{~min}$ for the original experiment in Section 4.2 (see Figure 7.) This suggests that the performance of the Edgartown Channel experiments depends strongly on the realizations of observation noise. Ultimately, these results are likely due to subtle interactions between the effects described here; this is typical in data assimilation experiments with nonlinear systems, which often arise in Lagrangian data assimilation.

\section{Results from a field experiment}

\subsection{Setup}

The trajectories of surface drifters released in Katama Inlet on Aug 22 (Inlet Trajectories in Figure 3) and in Edgartown Channel Aug 20 (Channel Trajectories in Figure 3) are assimilated to estimate the friction in Katama Inlet. Prior to reviewing the results of the assimilation, the performance of the model is tested with the original value $n=0.035 \mathrm{~s} / \mathrm{m}^{1 / 3}$. The simulated kinetic energy from that experiment in the inlet is compared with the kinetic energy observed at 10 locations in the system (Figure 11). The model kinetic energy at each sensor location is calculated 

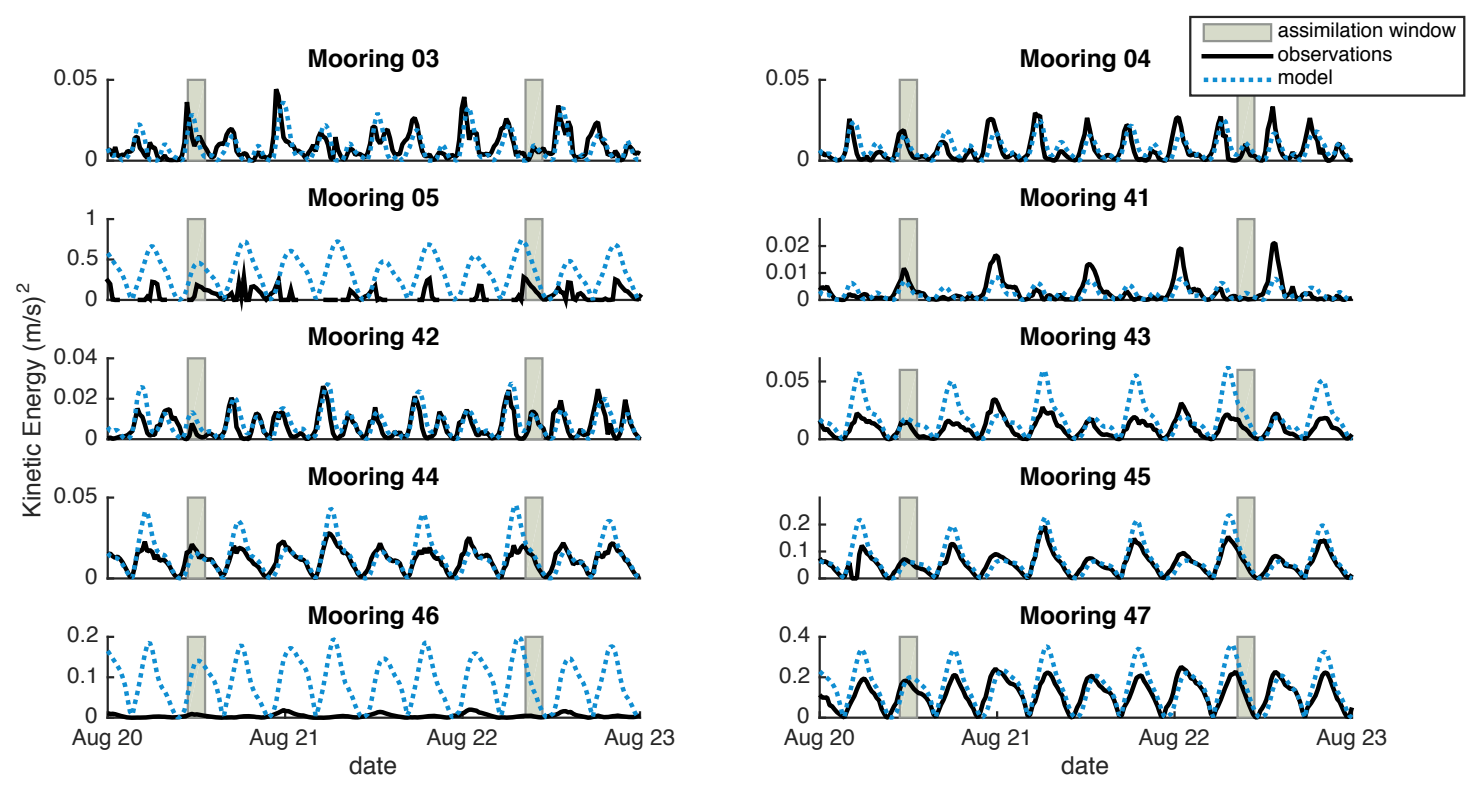

Mooring 45

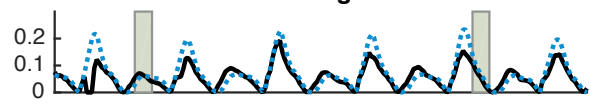

Mooring 47

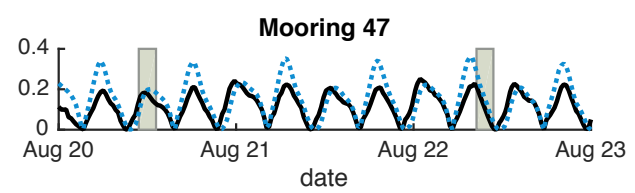

Figure 11: Observed (solid black curves) and simulated (dashed blue curves, $n=0.035$ ) kinetic energy versus time for 3 days in 2013. The shaded boxes are times during which drifters were deployed. The location of each comparison is given by the mooring number at the top of each panel, which corresponds to a sensor on the map in Figure 3. Note differences in scales of y-axes.

by interpolating the simulated velocity between nearby grid points. The observed kinetic energy is calculated from currents measured about $0.8 \mathrm{~m}$ above the seafloor in water depths $<2 \mathrm{~m}$ and from a depth average of the nearly uniform-in-the-vertical profiles in depths $>2 \mathrm{~m}$ (Orescanin et al., 2014).

The largest discrepancies between simulations with $n=0.035$ and observations are at locations 05 and 46, both close to Katama Inlet (Figure 3). The value $n=0.035 \mathrm{~s} / \mathrm{m}^{1 / 3}$ was based on observations in 2011, but the inlet lengthened, narrowed, and shoaled by 2013, resulting in a significant change in $n$ (Orescanin et al., 2016). Instead of re-tuning $n$ with the 2013 in-situ observations, $n$ is estimated by assimilating drifter trajectories into the model. 
Two experiments are performed - the first assimilates drifter observations in Katama Inlet, and the second assimilates drifter observations in Edgartown Channel. The model ensemble is initialized with a mean of $n=0.035 \mathrm{~s} / \mathrm{m}^{1 / 3}$ and a standard deviation of $0.005 \mathrm{~s} / \mathrm{m}^{1 / 3}$. The observation error is set at $\sigma_{R}=25 \mathrm{~m}$, as in the synthetic experiments.

Drifter data are available every second, but results from the synthetic runs (Section 4) suggest that this is more frequent than necessary since assimilating data every 1 min was sufficient for successful estimation in those experiments. Additionally, the EnKF assumes that observation errors are uncorrelated in time; if drifter positions are sampled every $1 \mathrm{sec}$, it is not clear that this assumption will hold. Thus, $\Delta t=1.0$ min for the channel drifter data on Aug 20, and $\Delta t=0.5$ min for the inlet drifter data on Aug 22 due to the shorter trajectories (Figure 3). Synthetic experiments with $\Delta t=0.5 \mathrm{~min}$ for the inlet drifters (not shown) demonstrate very similar results to those with $\Delta t=1.0 \mathrm{~min}$.

On Aug 20, ten drifters were deployed in the channel at 10:50 am and recovered at 1:10 pm. On Aug 22, the drifters were deployed in several relatively short releases in the inlet. Twelve drifters are assimilated from 8:31 until 8:48 am (Assimilation Round 1), at which point each ensemble member is evolved forward until 9:12 am with the final estimate of friction from Round 1. At 9:12 am, the next wave of ten drifters are assimilated for 10 minutes (Round 2). In Round 3, nine drifters are assimilated from 9:42 until 9:47am, and in Round 4, nine drifters are assimilated from 9:59 until 10:20 am. Note that the number of drifters assimilated in each round is not constant, because not every drifter was released at the exact same time nor did they all provide meaningful trajectories. Thus, only drifters that provided trajectories during overlapping time windows are assimilated. 


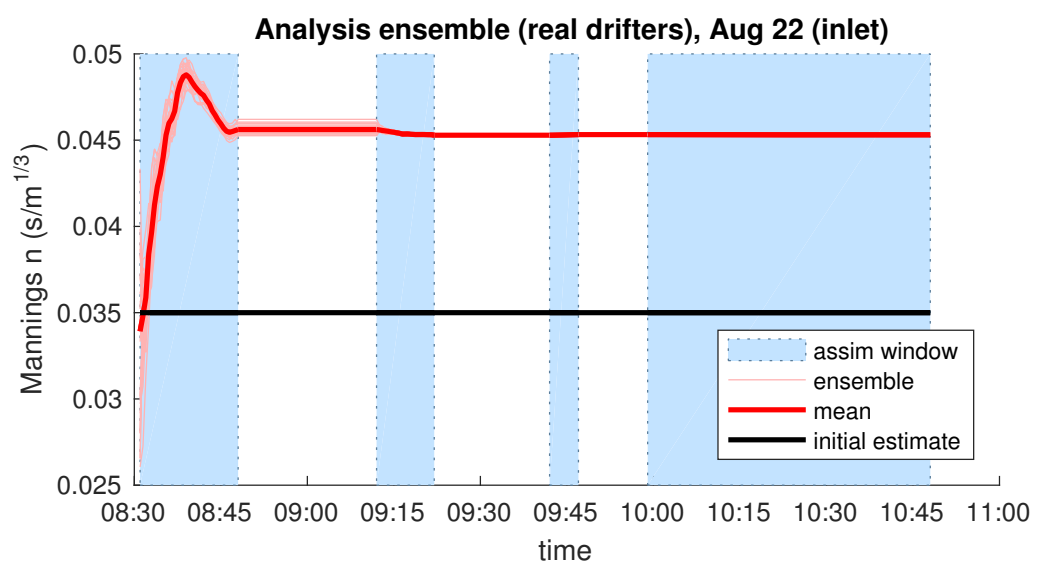

Figure 12: Ensemble (thin light red curves) and mean (thick red curves) estimates of Manning's $n$ from assimilating drifters within Katama Inlet versus time, with the initial estimate of $n=$ $0.035 \mathrm{~s} / \mathrm{m}^{1 / 3}$ (black horizontal line, the value found for the 2011 data (Orescanin et al., 2016)). Blue shaded regions are assimilation windows and unshaded regions are time periods in which the ensemble estimates of $n$ were kept constant.

\subsection{Results and discussion}

Manning's $n$ estimated by assimilating the Inlet Trajectories converges to $n=$ $0.045 \mathrm{~s} / \mathrm{m}^{1 / 3}$ (Figure 12), higher than the 2011 estimated value of $0.035 \mathrm{~s} / \mathrm{m}^{1 / 3}$ (Orescanin et al., 2016). Without assimilation and with $n=0.035$, the model over-predicts the kinetic energy at almost every in-situ sensor location (Figure 13). By assimilating drifter data, the model is closer to the in-situ observations at most locations, especially at sensors 05 and 47, located close to Katama Inlet (Figure 3). Specifically, since the observed drifters are traveling more slowly than the simulated drifters within the assimilation, the EnKF analysis increases the drag coefficient to diminish the mismatch between the observed drifters and the simulated drifters.

Figures 12 and 13 show how the estimate of $n$ and the associated kinetic energy change during assimilation, as $n$ is updated. In addition, another simulation is restarted on Aug 20 and run for three full days with the final estimated value of 


\section{Aug 22 (inlet drifters)}
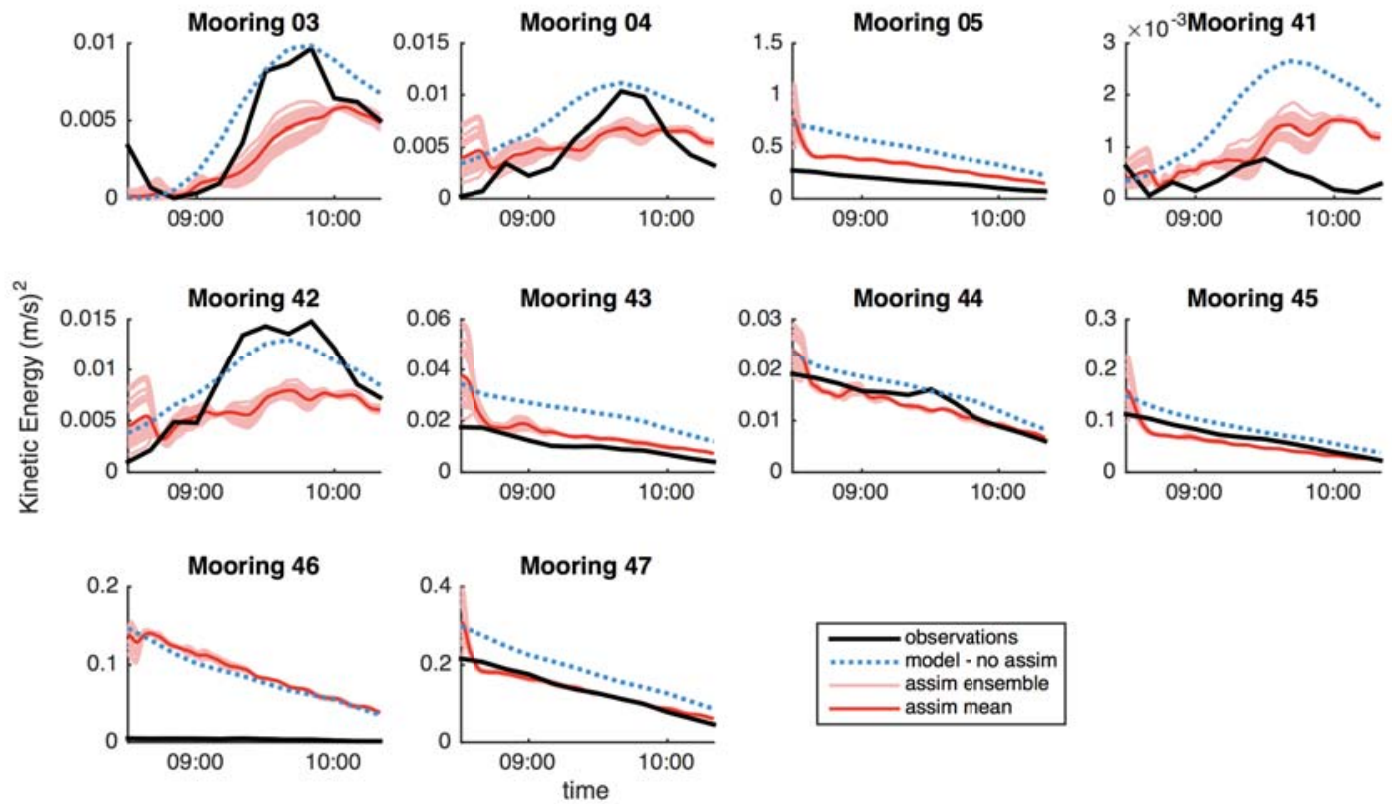

Figure 13: Kinetic energy versus time for observations (black curves), the model with no assimilation and $n=0.035 \mathrm{~s} / \mathrm{m}^{1 / 3}$ (dashed blue curves), and ensemble (thin light red curves) and mean (thick red curve) estimates of $n$ from assimilating drifters within Katama Inlet on Aug 22 versus time at each sensor location (numbers on top of each panel refer to sensor locations in the map in Figure 10). 
$n=0.045 \mathrm{~s} / \mathrm{m}^{1 / 3}$. Model skill is quantified by the root mean square error (RMSE, averaged over Aug 20-22) in kinetic energy relative to that observed with the in-situ sensors. At each sensor location, the observed kinetic energy at time $t$ is calculated as $K E_{o b s}(t)=1 / 2\left(u_{o b s}(t)^{2}+v_{o b s}(t)^{2}\right)$ for $u_{o b s}, v_{o b s}$ observed latitudinal and meridional current velocities, respectively. Similarly, the modeled kinetic energy $K E_{\text {sim }}(t)=$ $1 / 2\left(u_{\text {sim }}(t)^{2}+v_{\text {sim }}(t)^{2}\right)$ is calculated by interpolating the simulated velocity to the sensor locations. The RMSE is defined as

$$
R M S E=\left(\frac{\sum_{t=t_{0}}^{t_{f}}\left(K E_{o b s}(t)-K E_{s i m}(t)\right)^{2}}{\sum_{t=t_{0}}^{t_{f}}\left(K E_{\text {obs }}(t)\right)^{2}}\right)^{1 / 2}
$$

over the time period from $t_{0}$ to $t_{f}$. Relative to the simulation with $n=0.035 \mathrm{~s} / \mathrm{m}^{1 / 3}$, the simulation with the assimilated parameter $n=0.045 \mathrm{~s} / \mathrm{m}^{1 / 3}$ yields improved kinetic energy estimates at nearly every mooring, with the most significant improvement at Mooring 05, in Katama Inlet (Table 1).

In contrast, the estimate of $n$ in Katama Inlet from assimilating drifter trajectories in Edgartown Channel does not converge, and at the end of the time window $n=0.018 \mathrm{~s} / \mathrm{m}^{1 / 3}$ (Figure 14), significantly lower than the value estimated by assimilating drifters in the inlet, and lower than the initial estimate of $n=0.035 \mathrm{~s} / \mathrm{m}^{1 / 3}$. Unlike at the time of the Katama Inlet drifters' release, at the time of the drifters' release in Edgartown Channel the model simulation underestimates the observed kinetic energy at 7 of the 10 in-situ sensors (Figure 15). In particular, the original model underestimates the kinetic energy at sensors 03, 04, and 41 in Edgartown Channel (see Figure 3 for locations), where the drifters were released, although the kinetic energy at sensor 42 (also near the channel) is overestimated. The assimilation seeks to diminish this initial mismatch between the observed and simulated drifter trajectories by increasing the kinetic energy via decreasing the drag coefficient. As a 


\begin{tabular}{cccc}
\hline \hline Sensor & $n=0.035$ & $n=0.018$ & $n=0.045$ \\
\hline 03 & 0.007 & 0.013 & 0.007 \\
04 & 0.006 & 0.012 & 0.005 \\
05 & 0.371 & 0.888 & 0.234 \\
41 & 0.003 & 0.003 & 0.004 \\
42 & 0.005 & 0.013 & 0.004 \\
43 & 0.014 & 0.042 & 0.007 \\
44 & 0.007 & 0.014 & 0.006 \\
45 & 0.035 & 0.105 & 0.025 \\
46 & 0.100 & 0.096 & 0.095 \\
47 & 0.067 & 0.179 & 0.045 \\
\hline
\end{tabular}

Table 1: Normalized root mean squared error of kinetic energy between model simulations with given $n$ (units s/ $\mathrm{m}^{1 / 3}$ ) and the in-situ observations between Aug 20 and 22.

result, towards the end of the assimilation period, both the original simulation with $n=0.035 \mathrm{~s} / \mathrm{m}^{1 / 3}$ and the assimilated simulations overestimate the observed kinetic energy (Figure 15).

The model run with the final value of $n=0.018 \mathrm{~s} / \mathrm{m}^{1 / 3}$ has higher RMSE relative to the observed kinetic energy than the model using $n$ estimated by assimilating drifters in the inlet (Table 1), with the biggest errors at sensor 05 in the inlet. To test if the initial discrepancy in kinetic energy is indeed a driving factor in the results of the assimilation, channel drifters are assimilated beginning at 12:00 pm (rather than at 10:50 am), when the model changes from underestimating the observed kinetic energy to either overestimating or accurately estimating the observed energy (Figure 15). The model is initialized with $n=0.035 \mathrm{~s} / \mathrm{m}^{1 / 3}$, and run over the window 


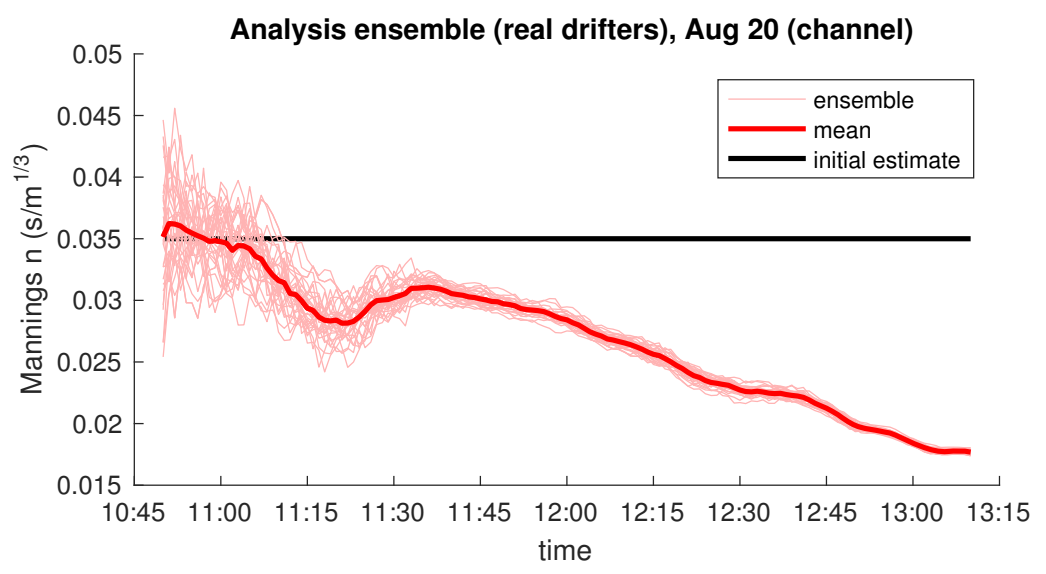

Figure 14: Ensemble (thin light red curves) and mean (thick red curve) estimates of Manning's $n$ in Katama Inlet from assimilating drifters in Edgartown Channel on Aug 20 as a function of time. The black line is the initial estimate $n=0.035 \mathrm{~s} / \mathrm{m}^{1 / 3}$.

from 12:00 to 1:10 pm (Figure 16).

In this case, the estimate of $n$ oscillates and decreases initially, and after $1 \mathrm{hr}$ returns to the initial value of $n=0.035 \mathrm{~s} / \mathrm{m}^{1 / 3}$ (although the ensemble may not have converged; Figure 16). This is because the model is not consistently over- or under-estimating the observed kinetic energy at the start of the window, and thus the assimilated ensemble does not increase or decrease the estimate of $n$ by the end of the assimilation.

These results suggest that the assimilation outcome can depend on the time and location of drifter deployment. Because the parameter of interest is the friction in a specific part of the domain (Katama Inlet), when drifters are deployed near or in that region, the assimilation performs better. For the experiments with drifters deployed in Edgartown Channel, the results depend on when the assimilation begins. This is linked to whether the model over- or under-estimates the kinetic energy at the beginning of the assimilation window. Further experiments would help determine 
Aug 20 (channel drifters)
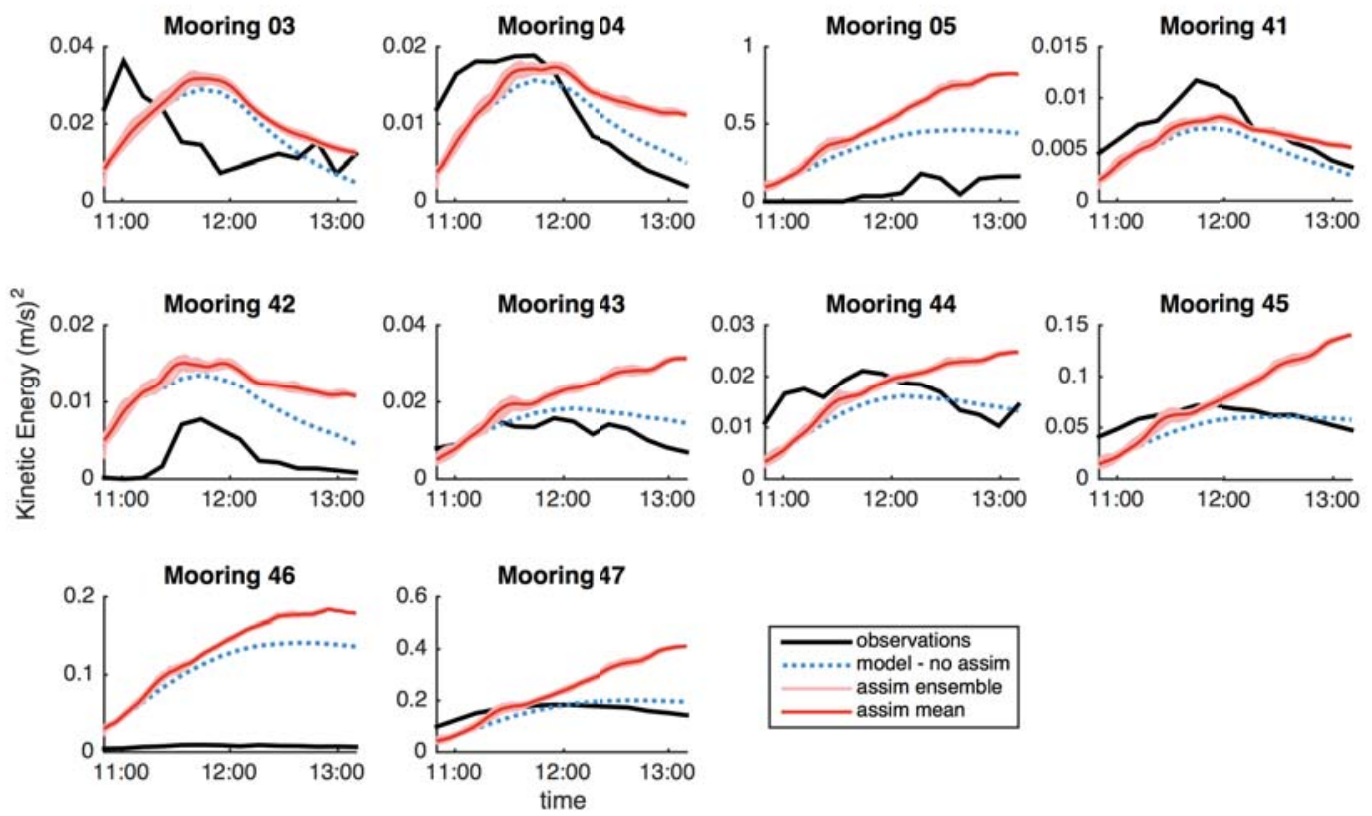

Figure 15: Kinetic energy versus time for observations (black curves), the model with no assimilation and $n=0.035 \mathrm{~s} / \mathrm{m}^{1 / 3}$ (dashed blue curves), and ensemble (thin light red curves) and mean (thick red curve) estimates of $n$ in the inlet from assimilating drifters within Edgartown Channel on Aug 20 versus time at each sensor location (numbers on top of each panel refer to sensor locations in the map in Figure 3). 


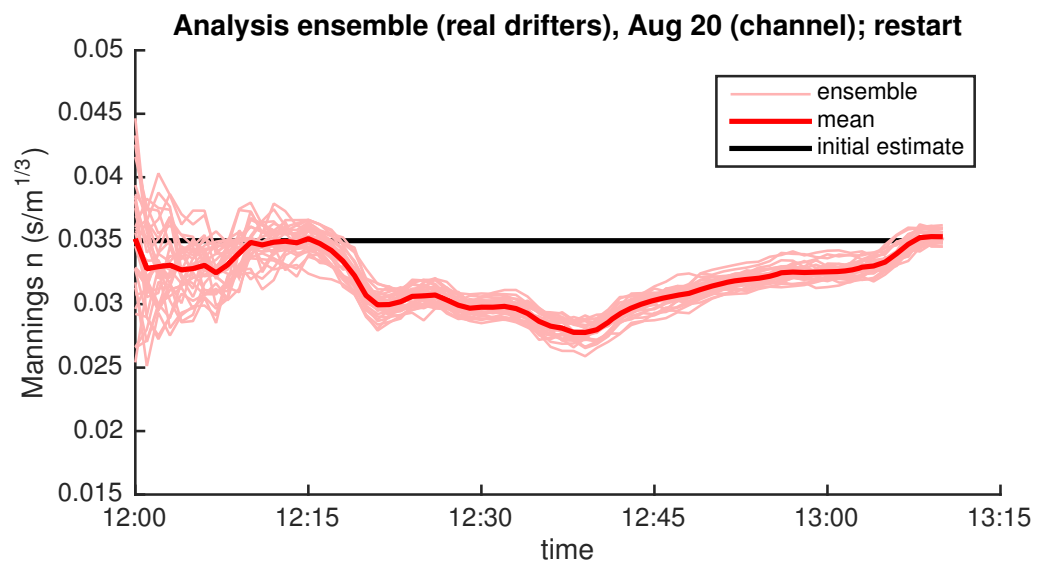

Figure 16: Ensemble (thin light red curves) and mean (thick red curve) estimates of Manning's $n$ in Katama Inlet from assimilating drifters in Edgartown Channel beginning at 12:00 pm on Aug 20 versus time. The black line is the initial estimate $n=0.035 \mathrm{~s} / \mathrm{m}^{1 / 3}$.

the relative importance of drifter deployment location and the difference in observed and simulated kinetic energy at the beginning of the assimilation window.

Note that these experiments do not include any covariance localization, a common method for reducing artificial correlations between spatially-distant regions of the domain, since the parameter of interest covers an entire subregion that may or may not include the drifter trajectories. Thus, these results demonstrate how the assimilation behaves when drifter observations in Edgartown Channel are allowed to update $n$ in Katama Inlet without any constraints. Imposing localization in the Edgartown Channel experiments would likely slow the time to convergence without changing the overall behavior of the ensemble estimate of $n$.

\section{Conclusions}

Trajectories of drifters are assimilated into a numerical model (ADCIRC) to estimate the friction (Manning's $n$ ) in Katama Inlet, which affects circulation in tidally- 
dominated Katama Bay. Synthetic observation experiments demonstrate the ability of the assimilation method to estimate Manning's $n$ using only trajectories of passive Lagrangian drifters. The performance of the assimilation is greatest when the drifters are located near the region for which $n$ is estimated. When the synthetic drifters are located in a different region (Edgartown Channel), away from the Katama Inlet region for which $n$ is estimated, the assimilation performance decreases, likely owing to interactions between the intrinsic adjustment time of the bay, sensitivity to observational noise, and nonlinear effects within the data assimilation method. This is supported by the investigations with identical setups but different realizations of observational noise (Section 4.3): the two realizations of the Katama Inlet experiment were qualitatively indistinguishable, while the two Edgartown Channel experiments differed significantly.

There are larger differences in the outcomes when real drifter data are assimilated, depending on whether drifters from Katama Inlet or Edgartown Channel are assimilated. Assimilation of trajectories observed from drifters released near Katama Inlet converges to a larger inlet drag coefficient than the 2011 value. Throughout the system, the corresponding simulated kinetic energy with the assimilated $n$ is often closer to the observed kinetic energy than simulations with the 2011 value. In contrast, when trajectories observed from drifters released in Edgartown Channel in 2013 are assimilated, $n$ is reduced and the kinetic energy estimates are not as accurate. This is partially due to the mismatch between the simulated (initialized with the 2011 value of $n$ ) and observed kinetic energy at the beginning of the assimilation window, and partially due to the larger spatial distance between the observations and the region for which $n$ is estimated. These results are also sensitive to the time the drifters are released in the channel.

Differences in assimilation performance between the synthetic and real experi- 
ments are likely due to unmodeled processes in the real experiment that may have a larger effect on the assimilation when the observations are far from the region of interest, owing to higher sensitivity to noise. Thus, an OSSE's ability to provide guidance decreases with increasing distance between observations and the region of interest.

The initial numerical circulation model used bathymetry measured in 2013 and a parameter tuned for kinetic energy measurements in 2011. The Katama Bay domain changed significantly in the area of Katama Inlet between 2011 and 2013 (recall Figures $1 \mathrm{~B}$ and $\mathrm{C}$ ), and the goal was to improve the parameter estimate $n$ from 2011 to represent the 2013 situation. Results depend on both when and where drifters are observed: if one wishes to estimate a local parameter in a model, then it is best to deploy drifters in that region. Ultimately, assimilation of real drifter trajectory data in Katama Inlet provides an improved estimate of $n$ in the inlet, based on comparisons between observed kinetic energy in 2013 and kinetic energy from the model simulations with the 2011 and 2013 estimates of the parameter. While Eulerian data are used to judge the performance of the assimilation, they are not necessary for the actual computation of the parameter.

\section{Acknowledgments}

This work was supported by: Department of Defense Multidisciplinary University Research Initiative (MURI) [grant N000141110087], administered by the Office of Naval Research; the National Science Foundation (NSF); the National Oceanic and Atmospheric Administration (NOAA); NOAA's Climate Program Office; the Department of Energy's Office for Science (BER); and the Assistant Secretary of Defense (Research \& Development). The authors would also like to thank the PVLAB field 
crew for helping obtain the observations. Finally, the authors gratefully acknowledge the helpful comments and suggestions from three anonymous reviewers.

Apotsos, A., Raubenheimer, B., Elgar, S., , Guza, R., 2008. Wave-driven setup and alongshore flows observed onshore of a submarine canyon. Journal of Geophysical Research 113 (C07025).

Apte, A., Jones, C., Stuart, A., 2008. A Bayesian approach to Lagrangian data assimilation. Tellus 60A, 336-347.

Biron, P. M., Robson, C., Lapointe, M. F., Gaskin, S. J., 2004. Comparing different methods of bed shear stress estimates in simple and complex flow fields. Earth Surface Processes and Landforms 29 (11), 1403-1415.

Chen, J.-L., Hsu, T.-J., Shi, F., Raubenheimer, B., Elgar, S., 2015. Hydrodynamic and sediment transport modeling of New River Inlet (NC) under the interaction of tides and waves. Journal of Geophysical Research: Oceans 120 (6), 4028-4047. URL http://dx.doi.org/10.1002/2014JC010425

Cheng, R. T., Ling, C.-H., Gartner, J. W., Wang, P. F., 1999. Estimates of bottom roughness length and bottom shear stress in South San Francisco Bay, California. Journal of Geophysical Research: Oceans 104 (C4), 7715-7728.

URL http://dx.doi.org/10.1029/1998JC900126

Dias, J. M., Sousa, M. C., Bertin, Z., Fortunato, A. B., Oliveira, A., 2009. Numerical modeling of the impact of the Ancao Inlet relocation (Ria Formosa, Portugal. Env. Model. \& Soft. 24, 711-725. 
Evensen, G., May 1994. Sequential data assimilation with a nonlinear quasigeostrophic model using Monte Carlo methods to forecast error statistics. J. Geophys. Res.: Oceans 99 (C5), 10143-10162.

Evensen, G., 2003. The ensemble Kalman filter: theoretical formulation and practical implementation. Ocean Dynamics 53, 343-367.

Feddersen, F., Guza, R. T., Elgar, S., Herbers, T. H. C., 2000. Velocity moments in alongshore bottom stress parameterizations. Journal of Geophysical Research: Oceans 105 (C4), 8673-8686.

URL http://dx.doi.org/10.1029/2000JC900022

Fiorentino, L., Olascoaga, M., Reniers, A., Feng, Z., Beron-Vera, F., MacMahan, J., 9 2012. Using Lagrangian Coherent Structures to understand coastal water quality. Continental Shelf Research 47, 145-149.

Friedrichs, C. T., 1995. Stability shear stress and equilibrium cross-sectional geometry of sheltered tidal channels. Journal of Coastal Research 11 (4), 1062-1074.

Friedrichs, C. T., Madsen, O. S., 1992. Nonlinear diffusion of the tidal signal in frictionally dominated embayments. J. Geophys. Res. 97, 5637-5650.

Herbers, T. H. C., Jessen, P. F., Janssen, T. T., Colbert, D. B., MacMahan, J. H., 2012. Observing ocean surface waves with gps-tracked buoys. Journal of Atmospheric and Oceanic Technology 29 (7), 944-959.

Honnorat, M., Monnier, J., Riviére, N., Huot, É., Dimet, F.-X. L., March 2010. Identification of equivalent topography in an open channel flow using Lagrangian data assimilation. Computing and Visualization in Science 13 (3), 111-119. 
Houtekamer, P. L., Mitchell, H. L., 2001. A sequential ensemble Kalman filter for atmospheric data assimilation. Monthly Weather Review 129, 123-137.

Ide, K., Kuznetsov, L., Jones, C., 2002. Lagrangian data assimilation for point vortex systems. J. Turbul. 3 (053).

Jacobs, G. A., Bartels, B. P., Bogucki, D. J., Beron-Vera, F. J., Chen, S. S., Coelho, E. F., Curcic, M., Griffa, A., Gough, M., Haus, B. K., Haza, A. C., Helber, R. W., Hogan, P. J., Huntley, H. S., Iskandarani, M., Judt, F., Jr., A. K., Laxague, N., Valle-Levinson, A., Jr., B. L. L., Mariano, A. J., Ngodock, H. E., Novelli, G., Olascoaga, M. J., Özgökmen, T. M., Poje, A. C., Reniers, A. J., Rowley, C. D., Ryan, E. H., Smith, S. R., Spence, P. L., Thoppil, P. G., Wei, M., 2014. Data assimilation considerations for improved ocean predictability during the Gulf of Mexico Grand Lagrangian Deployment (GLAD) . Ocean Modelling 83, 98 - 117.

Kalnay, E., 2003. Atmospheric modeling, data assimilation, and predictability. Cambridge University Press.

Kim, S.-C., Friedrichs, C., Maa, J.-Y., Wright, L., 2000. Estimating bottom stress in tidal boundary layer from acoustic doppler velocimeter data. Journal of Hydraulic Engineering 126 (6), 399-406.

Kraus, N. C., Militello, A., 1999. Hydraulic study of multiple inlet system: East Matagorda Bay, Texas. Journal of Hydraulic Engineering 125, 224-232.

Kurapov, A. L., Allen, J. S., Egbert, G. D., Miller, R. N., Kosro, P. M., Levine, M. D., Boyd, T., Barth, J. A., 2005. Assimilation of moored velocity data in a model of coastal wind-driven circulation off Oregon: Multivariate capabilities. Journal of Geophysical Research 10 (C10S08). 
Kuznetsov, L., Ide, K., Jones, C., October 2003. A method for assimilation of Lagrangian data. Mon. Wea. Rev. 131, 2247-2260.

Landon, K. C., Wilson, G. W., Özkan-Haller, H. T., MacMahan, J. H., 2014. Bathymetry estimation using drifter-based velocity measurements on the Kootenai River, Idaho. Journal of Atmospheric and Oceanic Technology 31 (2), 503-514.

Luettich, R., Westerink, J., June 1991. A solution for the vertical variation of stress, rather than velocity, in a three-dimensional circulation model. International Journal for Numerical Methods in Fluids 12 (10), 911-928.

URL http://dx.doi.org/10.1002/fld.1650121002

MacMahan, J., Brown, J., Thornton, E., 2009. Low-cost handheld global positioning systems for measuring surf zone currents. Journal of Coastal Research 25, 744-754.

Madsen, H., Cañizares, R., 1999. Comparison of extended and ensemble Kalman filters for data assimilation in coastal area modelling. International Journal for Numerical Methods in Fluids 31 (6), 961-981.

URL http://dx.doi.org/10.1002/(SICI) 1097-0363(19991130)31:6<961: :AID-FLD907>3.0.CD

Mariano, A. J., Griffa, A., Özgökmen, T. M., Zambianchi, E., 2002. Lagrangian analysis and predictability of coastal and ocean dynamics 2000. Journal of Atmospheric and Oceanic Technology 19 (7), 1114-1126.

URL http://dx. doi .org/10.1175/1520-0426(2002)019<1114:LAAPOC>2.0.CD;2

Mayo, T., Butler, T., Dawson, C., Hoteit, I., 2014. Data assimilation within the Advanced Circulation (ADCIRC) modeling framework for the estimation of Manning's friction coefficient. Ocean Modelling 76, 43-58. 
McCarroll, R. J., Brander, R. W., MacMahan, J. H., Turner, I. L., Reniers, A. J. H. M., Brown, J. A., Bradstreet, A., Sherker, S., 2014. Evaluation of swimmerbased rip current escape strategies. Natural Hazards 71 (3), 1821-1846.

Mehta, A. J., Joshi, P. B., 1998. Tidal inlet hydraulics. Journal of Hydraulic Engineering 117, 1321-1338.

Mitchell, H. L., Houtekamer, P. L., Pellerin, G., 2002. Ensemble size, balance, and model-error representation in an ensemble Kalman filter. Monthly Weather Review 130 (11), 2791-2808.

URL http: //dx .doi .org/10.1175/1520-0493(2002) 130<2791:ESBAME>2.0. C0;2

Molcard, A., Griffa, A., Özgökmen, T., January 2005. Lagrangian data assimilation in multilayer primitive equation ocean models. J. Atmos. Oceanic Technol. 22, 70-83.

Molcard, A., Piterbarg, L. I., Griffa, A., Özgökmen, T., Mariano, A. J., March 2003. Assimilation of drifter observations for the reconstruction of the Eulerian circulation field. J. Geophys. Res. 108 (3056).

Molcard, A., Poje, A., Özgökmen, T., 2006. Directed drifter launch strategies for Lagrangian data assimilation using hyperbolic trajectories. Ocean Modelling 12, $268-289$.

Oke, P., Allen, J., Miller, R., Egbert, G., Kosro, P., 2002. Assimilation of surface velocity data into a primitive equation coastal ocean model. Journal of Geophysical Research: Oceans 107 (C9).

Orescanin, M. M., Elgar, S., Raubenheimer, B., 2016. Changes in bay circulation in an evolving multiple inlet system. Continental Shelf Research 124, 13:22. 
Orescanin, M. M., Raubenheimer, B., Elgar, S., July 2014. Observations of wave effects on inlet circulation. Continental Shelf Research 82, 37-42.

Roth, M., MacMahan, J., Reniers, A., Özgökmen, T., Woodall, K., Haus, B., submitted. Natural coastal barriers to surface material transport in the northern Gulf of Mexico. Continental Shelf Research.

Salman, H., Ide, K., Jones, C., 2008. Using flow geometry for drifter deployment in Lagrangian data assimilation. Tellus 60A, 321-355.

Salman, H., Kuznetsov, L., Jones, C., Ide, K., April 2006. A method for assimilating Lagrangian data into a shallow-water-equation ocean model. Mon. Wea. Rev. 134, $1081-1100$.

Sanford, T. B., Lien, R.-C., 1999. Turbulent properties in a homogeneous tidal bottom boundary layer. Journal of Geophysical Research: Oceans 104 (C1), 12451257.

URL http://dx.doi.org/10.1029/1998JC900068

Seim, H. E., Blanton, J. O., Gross, T., 2002. Direct stress measurements in a shallow, sinuous estuary. Continental Shelf Research 22 (11-13), 1565 - 1578, proceedings from the Tenth Biennial Conference on the Physics of Estuaries and Coastal Seas.

URL http://www.sciencedirect.com/science/article/pii/S0278434302000298

Slivinski, L., Spiller, E., Apte, A., Sandstede, B., 2015. A hybrid particle-ensemble Kalman filter for Lagrangian data assimilation. Monthly Weather Review 143 (1), $195-211$. 
Taillandier, V., Griffa, A., Poulain, P.-M., Béranger, K., 2006. Assimilation of Argo float positions in the north western Mediterranean Sea and impact on ocean circulation simulations. Geophysical Research Letters 33 (11), n/a-n/a, 111604.

URL http://dx.doi .org/10.1029/2005GL025552

Trowbridge, J. H., Geyer, W. R., Bowen, M. M., III, A. J. W., 1999. Near-bottom turbulence measurements in a partially mixed estuary: Turbulent energy balance, velocity structure, and along-channel momentum balance. Journal of Physical Oceanography 29 (12), 3056-3072.

URL http: //dx .doi.org/10.1175/1520-0485(1999)029<3056:NBTMIA>2.0.C0;2

Vernieres, G., Jones, C. K., Ide, K., 2011. Capturing eddy shedding in the Gulf of Mexico from Lagrangian observations. Physica D: Nonlinear Phenomena 240 (2), $166-179$.

Wei, M., Toth, Z., Wobus, R., Zhu, Y., Bishop, C. H., Wang, X., 2006. Ensemble Transform Kalman Filter-based ensemble perturbations in an operational global prediction system at NCEP. Tellus A 58 (1), 28-44.

URL http://dx.doi.org/10.1111/j.1600-0870.2006.00159.x

Wilson, G. W., Özkan-Haller, H. T., Holman, R. A., 2010. Data assimilation and bathymetric inversion in a two-dimensional horizontal surf zone model. Journal of Geophysical Research: Oceans 115 (C12), n/a-n/a, c12057.

URL http://dx.doi.org/10.1029/2010JC006286 